\title{
Nooj, um recurso didático para o estudo de "O Ano da Morte de Ricardo Reis"
}

\section{Carla Sofia Lima Barreira Araújo}

Instituto Politécnico de Bragança - IPB - ESEB Centro de Estudos em Letras - CEL - UTAD, Bragança, Portugal, carla.araujo@ipb.pt

\begin{abstract}
Resumo
Com sustentação teórica na Linguística de Corpus, este artigo tem como objetivo apresentar uma possibilidade de intervenção didática para o estudo do vocabulário de um romance de leitura integral obrigatória na disciplina de Português no $12{ }^{\circ}$ ano de escolaridade, "O Ano da morte de Ricardo Reis", de José Saramago. Deste modo, utilizamos o programa Nooj, disponivel on-line em www.nooj-association.org, que nos fornece uma lista dos tokens mais frequentes, a partir da qual identificamos as palavras-tema da obra, tendo em vista a delimitação de campos temáticos na obra "O Ano da morte de Ricardo Reis". A análise lexicométrica do romance "O Ano da morte de Ricardo Reis", de José Saramago, constitui uma possibilidade de operacionalização didática, que apresenta o programa computacional Nooj como um recurso didático possível, dado que faculta o conhecimento cabal da tessitura lexical da obra, permitindo aos alunos o desenvolvimento da sua competência lexical, através de práticas pedagógicas de análise textual que rentabilizam as potencialidades das novas tecnologias e convocam a participação ativa de alunos e professores, tendo em vista a aprendizagem efetiva e consolidada da língua portuguesa.
\end{abstract}

Palavras-chave: Ensino do Português; Nooj; Palavras-tema; Campos temáticos; homonímia; polissemia.

\section{Introdução}

Este artigo é constituído por três partes e visa apresentar uma possibilidade de intervenção didática para o estudo do vocabulário de um romance de leitura integral obrigatória na disciplina de Português no 12. ${ }^{\circ}$ ano de escolaridade, "O Ano da morte de Ricardo Reis", de José Saramago (Saramago, 1984), recorrendo ao Nooj (Silberztein, 2003), programa computacional de análise lexical. 
Nesse sentido, começaremos por apresentar os dados gerais do corpus e organizar uma listagem de palavras-tema, partindo da listagem dos tokens por ordem decrescente de frequência. A análise lexicométrica de "O Ano da morte de Ricardo Reis", de José Saramago, termina com a apresentação dos campos temáticos, delimitados a partir das respetivas palavras-tema.

Na última parte do trabalho, exporemos uma proposta pedagógica que apresenta o Nooj, como um possível recurso didático para o estudo de "O Ano da Morte de Ricardo Reis", de José Saramago.

\section{Análise lexicométrica do romance "O Ano da morte de Ricardo Reis", de José Saramago}

Para concretizarmos o presente trabalho de análise lexicométrica do romance "O Ano da Morte de Ricardo Reis", de José Saramago, utilizamos o Nooj, programa computacional de análise lexical, disponível online em www.nooj4nlp.net (Mota, Carvalho \& Barreiro 2016).

Seguidamente, partindo da análise linguística efetuada pelo Nooj, apresentaremos a análise lexicométrica do romance "O Ano da Morte de Ricardo Reis", de José Saramago.

Iniciada a análise linguística, o Nooj apresenta-nos os dados gerais caracterizadores do texto, patentes na tabela 1 .

Tabela 1. Dados Gerais do Corpus - "O Ano da morte de Ricardo Reis"

\begin{tabular}{|l|l|}
\hline \multicolumn{2}{|c|}{ Dados Gerais do Corpus - "O Ano da morte de Ricardo Reis" } \\
\hline N. ${ }^{\mathbf{0}}$ de caracteres & $\begin{array}{l}801106 \text { (634833 letras; 138836 espaços em branco; 27426 } \\
\text { outros delimitadores) }\end{array}$ \\
\hline Tokens & 169122 \\
\hline Word forms & 141685 \\
\hline Delimiters & 27426 \\
\hline Anotações & 478123 \\
\hline Ambiguidade & 10380 tipos diferentes de ambiguidade \\
\hline Unidades linguísticas não ambíguas & 6281 \\
\hline
\end{tabular}

O programa Nooj analisou os tokens e as respetivas frequências. Os tokens podem ser apresentados por ordem decrescente da sua frequência e/ou alfabeticamente. 
Através da análise dos itens mais frequentes, verificámos que, tal como ocorre na maioria dos corpora, as formas mais frequentes são palavras pertencentes às classes fechadas (Mendes, 2013, p. 257). Deste modo, em "O Ano da Morte de Ricardo Reis", os cinco tokens mais frequentes são os seguintes: "A"/"a", "Que"/"que, "De"/“de", "O"/“o", "E"/“e", apresentando uma frequência de 5095, 4952, 4744, 4554, 3524, respetivamente.

$\mathrm{Na}$ análise dos tokens mais frequentes, é importante salientar que o Nooj, tal como se verifica na maioria das aplicações de cariz lexicométrico, procede à distinção entre maiúsculas e minúsculas, considerando, separadamente, cada forma diferente do mesmo lema.

Nesse sentido, o token que surge no primeiro lugar da lista por ordem decrescente de frequência, "a", possui uma frequência de 4926, à qual se soma a frequência da forma "A", correspondente a 169. Igualmente, o token que surge no segundo lugar da lista por ordem decrescente de frequência, "que", apresenta uma frequência de 4873, apresentando a forma "Que" 79 de frequência.

A partir da análise da lista de tokens mais frequentes, selecionámos os 60 tokens que surgem por ordem decrescente de frequência, tendo como critérios palavras pertencentes às classes abertas (Raposo, 2013). Deste modo, organizámos uma listagem de palavras-tema (Genouvrier \& Peytard, 1974) e das respetivas frequências, como se apresenta na tabela 2, onde apresentamos a listagem de tokens constituída por nomes comuns, adjetivos e verbos principais, designados itens lexicais ou itens plenos (Mendes, 2013). Estes itens integram palavras denotadoras de entidades que pertencem ao universo extra-linguístico, por conseguinte veiculam um sentido descritivo, que viabiliza a delimitação de campos temáticos (Galisson \& Coste, 1983), no corpus em análise. Note-se que a palavra "tem/Tem", forma representativa do item lexical "ter", pode ocorrer com dois valores, ou seja, "o valor de verbo pleno de posse e o valor de verbo auxiliar" (Mendes, 2013, p. 250). A análise das concordâncias relativas a essa palavra revelou-se fundamental para sabermos se a respetiva forma remetia para verbo pleno ou para verbo auxiliar. No âmbito das 281 ocorrências do token "tem"/"Tem", verificou-se a predominância do valor de verbo pleno de posse. 
Nooj, um recurso didático para o estudo de "O Ano da Morte de Ricardo Reis"

Tabela 2. Listagem de Palavras-tema - "O Ano da morte de Ricardo Reis"

\begin{tabular}{|c|c|c|c|c|c|c|c|}
\hline Frequência & Token & Frequência & Token & Frequência & Token & Frequência & Token \\
\hline $363(28)$ & há (Há) & $158(11)$ & $\begin{array}{l}\text { sabe } \\
\text { (Sabe) }\end{array}$ & 109 & lado & $91(1)$ & vão (Vão) \\
\hline $266(15)$ & tem (Tem) & $160(7)$ & $\begin{array}{l}\text { pode } \\
\text { (Pode) }\end{array}$ & $104(5)$ & faz (Faz) & 90 & Gente \\
\hline 270 & tempo & $162(3)$ & $\begin{array}{l}\text { dias } \\
\text { (Dias) }\end{array}$ & 105 & dar & 90 & Mulher \\
\hline $234(21)$ & vai (Vai) & 162 & Palavras & $103(1)$ & $\begin{array}{l}\text { nome } \\
\text { (Nome) }\end{array}$ & 89 & Anos \\
\hline 237 (2) & $\begin{array}{l}\text { doutor } \\
\text { (Doutor) }\end{array}$ & $133(26)$ & $\begin{array}{l}\text { hotel } \\
\text { (Hotel) }\end{array}$ & 101 & vezes & 89 & Cabeça \\
\hline $226(13)$ & $\begin{array}{l}\text { senhor } \\
\text { (Senhor) }\end{array}$ & 151 & Porta & 100 & coisa & 88 & $\mathrm{Ir}$ \\
\hline 203 & vez & 147 & Olhos & $17(83)$ & $\begin{array}{l}\text { deus } \\
\text { (Deus) }\end{array}$ & $88(1)$ & $\begin{array}{l}\text { mulheres } \\
\text { (Mulheres) }\end{array}$ \\
\hline $202(1)$ & $\begin{array}{l}\text { homem } \\
\text { (Homem) }\end{array}$ & $142(1)$ & $\begin{array}{l}\text { mundo } \\
\text { (Mundo) }\end{array}$ & $95(2)$ & pai (Pai) & $82(7)$ & veio (Veio) \\
\hline $199(1)$ & $\begin{array}{l}\text { casa } \\
\text { (Casa) }\end{array}$ & $139(5)$ & $\begin{array}{l}\text { grande } \\
\text { (Grande) }\end{array}$ & 95 & homens & $87(1)$ & $\begin{array}{l}\text { pessoas } \\
\text { (Pessoas) }\end{array}$ \\
\hline $196(4)$ & dia (Dia) & $139(1)$ & $\begin{array}{l}\text { saber } \\
\text { (Saber) }\end{array}$ & 95 & lugar & $83(3)$ & deu (Deu) \\
\hline $194(1)$ & $\begin{array}{l}\text { dizer } \\
\text { (Dizer) }\end{array}$ & $132(6)$ & $\begin{array}{l}\text { tinha } \\
\text { (Tinha) }\end{array}$ & $94(2)$ & Caso & $83(1)$ & $\begin{array}{l}\text { morte } \\
\text { (Morte) }\end{array}$ \\
\hline $184(4)$ & $\begin{array}{l}\text { disse } \\
\text { (Disse) }\end{array}$ & $126(12)$ & $\operatorname{diz}(\mathrm{Diz})$ & 95 & verdade & 83 & Coisas \\
\hline 183 & ver & 136 & Fazer & $85(9)$ & $\begin{array}{l}\text { quer } \\
\text { (Quer) }\end{array}$ & 83 & Mãos \\
\hline 183 & vida & 118 & Quarto & $91(3)$ & $\begin{array}{l}\text { vem } \\
\text { (Vem) }\end{array}$ & 81 & Horas \\
\hline 166 & mão & $116(2)$ & $\begin{array}{l}\text { noite } \\
\text { (Noite) }\end{array}$ & 93 & falar & 81 & Palavra \\
\hline
\end{tabular}

$\mathrm{Na}$ primeira etapa de análise das palavras-tema, deparamo-nos com fenómenos de ambiguidade potencial, inerente à maior parte das formas linguísticas, uma vez que, na listagem dos tokens fornecida pelo Nooj, as palavras-tema não surgem integradas nos próprios contextos de ocorrência, por isso, foi necessário proceder à extração de 
concordâncias no Nooj. Assim, foram analisados todos os contextos de ocorrência de cada uma das palavras-tema do corpus e consultadas as definições patentes no dicionário ${ }^{1}$ relativas às mesmas.

Por conseguinte, as formas "como", que surge 803 vezes no corpus, e "Como", com 34 ocorrências, que podem dizer respeito à conjunção, ao advérbio interrogativo, ao nome masculino ou à forma dos verbos comer e comar, não integram a listagem de palavras-tema de "O Ano da morte de Ricardo Reis" (cf. tabela 2), uma vez que a maior parte dos contextos de ocorrência das mesmas remete para itens gramaticais, os quais, como referimos anteriormente, não se incluem no critério de seleção determinado. A mesma situação se verifica relativamente às formas "mas", com 649 ocorrências, e "Mas", que apresenta 71 ocorrências, dado que a análise das concordâncias relativas às mesmas nos permitiu verificar que se trata do item gramatical conjunção "mas" e não do item lexical nome masculino "mas".

De igual modo, das 345 ocorrências de "ser" e de 1 ocorrência de "Ser", apenas sete remetiam para o nome comum "ser" ("daquele que lhe deu o ser, senador que foi do partido"; "constante em meu pensamento, meu ser é a invisível curva traçada"; "a passagem para um não ser. Despiu a gabardina e o"; "mesmo se vê como um ser duplo, o Ricardo Reis limpo"; "Não lhe metemos dentro um ser humano. Daqui por uns anos"; "que lhes tinham dado o ser. Dantes era tudo muito mais"; "e contratorpedeiros. Era o único ser vivo no Alto de Santa"). Portanto, consideramos que a verificada baixa frequência de ocorrência como palavra plena não era suficiente para a forma "ser" integrar a listagem de palavras-tema.

$\mathrm{Na}$ lista de tokens mais frequentes, fornecida pelo Nooj, os tokens "ele", com 318 ocorrências, e "Ele", com 7 ocorrências, também se encontravam presentes, no entanto, a análise das respetivas concordâncias remete-nos para o item gramatical pronome pessoal "ele". Uma vez que estes tokens não dizem respeito aos itens lexicais "ele", nome masculino ou forma do verbo elar, também não integram a listagem de palavras-tema.

$\mathrm{Na}$ listagem de palavras-tema, também não se encontram os tokens "são", com 317 ocorrências, e "São", com 21 ocorrências, dado que, como nos casos acima apresentados, revelam uma baixa frequência de ocorrência como itens plenos - adjetivo ("sobretudo aquele santo que saiu são para o monte e de”); nome masculino (“duzentos engarrafadeiros, quatrocentos mineiros de São Pedro da Cova, quatrocentos conserveiros"; "santo a Portugal, lá está, São Portugal, e vem um príncipe"; "É para os lados de São João da Pesqueira, e a") - e uma elevada frequência como forma do verbo ser.

\footnotetext{
${ }^{1}$ Dicionário da Língua Portuguesa da Porto Editora ${ }^{\circledR}$ (versão on-line): http://www.infopedia.pt/.
} 
Igualmente, na lista de tokens mais frequentes, ocorrem "só", com 310 ocorrências, e "Só", que apresenta 14 ocorrências, todavia a consulta das respetivas concordâncias permitiu-nos constatar que a frequência mais elevada diz respeito a ocorrências que remetem para o advérbio "só", que configura um item gramatical. Dado que as ocorrências como item pleno, nome ou adjetivo, são reduzidas, estes tokens não integram a listagem de palavrastema. Também as formas "sua", com frequência de 304, e "Sua", com frequência 1, ocorrem sempre como item gramatical, ou seja, determinante e pronome possessivo, não se tendo observado ocorrências relativas ao item lexical, a forma do verbo suar.

Efetivamente, a leitura das concordâncias e a consulta do dicionário permitem identificar fenómenos de homonímia parcial (Chaves, 2013, p. 192). Por exemplo, veja-se, na tabela 2, a forma "casa"/"Casa", que apresenta 200 ocorrências". Perante esta forma, o observador interroga-se se a mesma remete para "casa" [verbo casar] ou "casa" [nome], em conformidade com o que se conclui na consulta do dicionário, ${ }^{2}$ que nos remete para a forma do verbo "casar" e para o nome "casa".

Partindo da observação das 200 concordâncias relativas à palavra-tema "casa"/"Casa" (surge uma vez com letra maiúscula), como podemos verificar na figura 1, conclui-se que apenas uma das ocorrências da forma "casa" corresponde ao verbo casar ("ninguém se batiza, ninguém se casa, o amor não existe, a"), sendo as restantes 199 formas pertencentes ao nome feminino singular de "casa".

Fig. 1 Concordâncias da palavra-tema "casa/Casa"

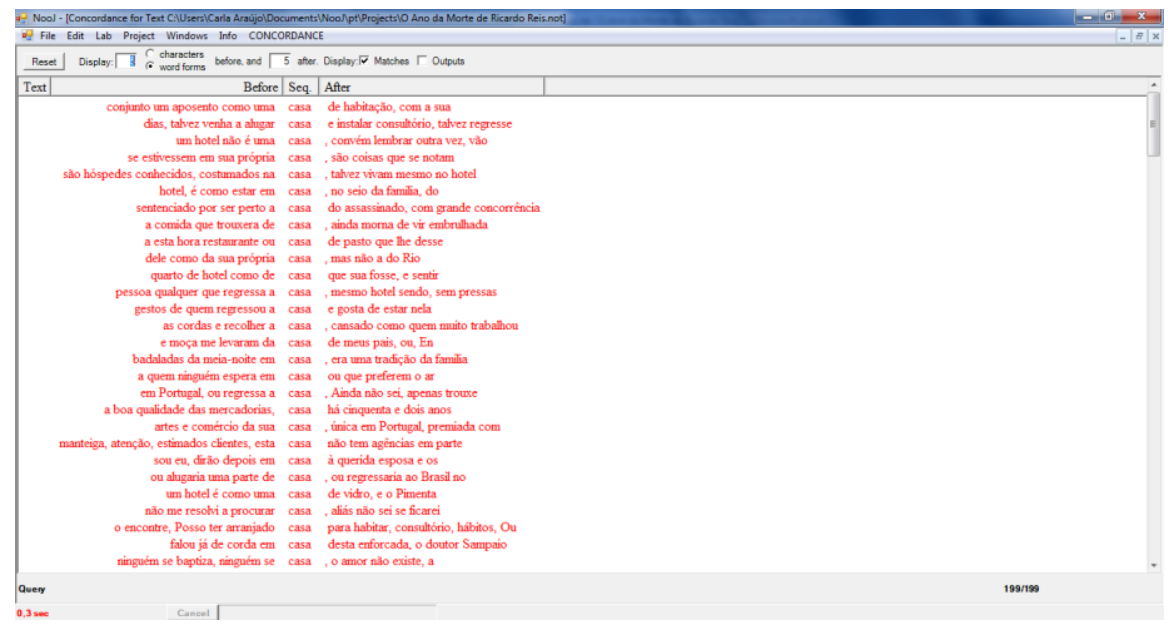

${ }^{2}$ casa in Dicionário infopédia da Língua Portuguesa [em linha]. Porto: Porto Editora, 2003-2018. [consult. 201806-05 10:45:32]. Disponível na Internet: https://www.infopedia.pt/dicionarios/lingua-portuguesa/casa 
Além disso, no Nooj, podemos também visualizar as palavras ambíguas (figura 2) e as palavras não ambíguas (figura 3), tendo acesso a todas as anotações produzidas para o corpus em estudo.

Fig. 2 Palavras ambíguas de "O Ano da morte de Ricardo Reis"

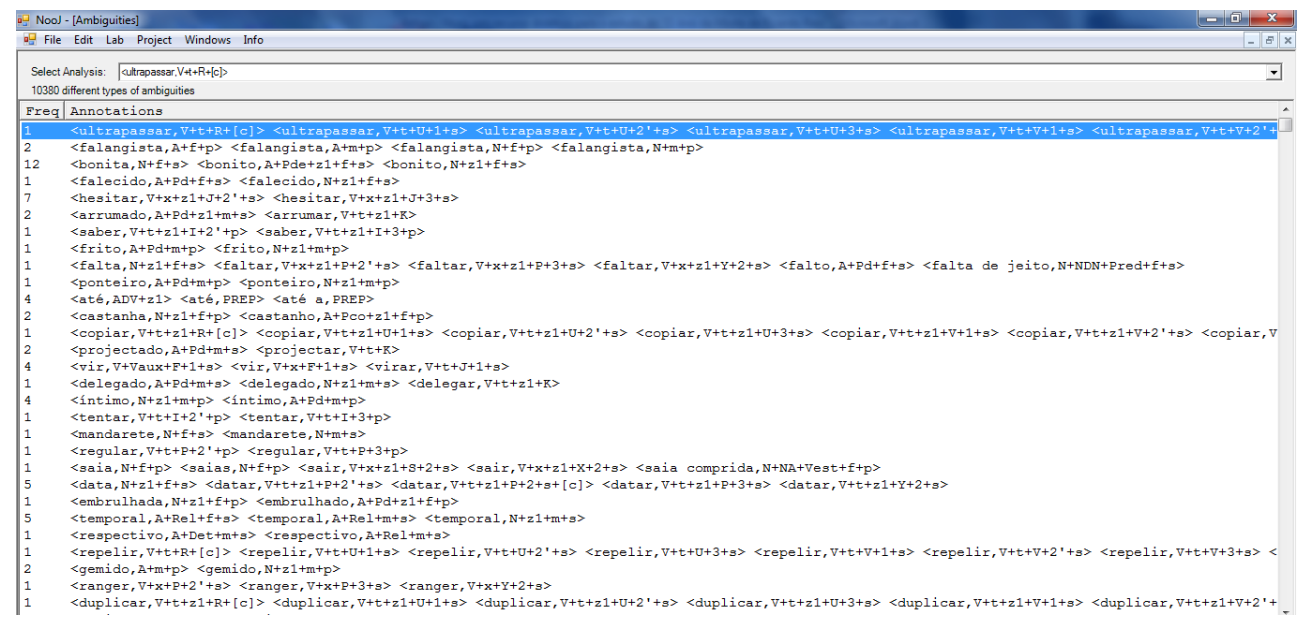

Fig. 3 Palavras não ambiguas de "O Ano da morte de Ricardo Reis"

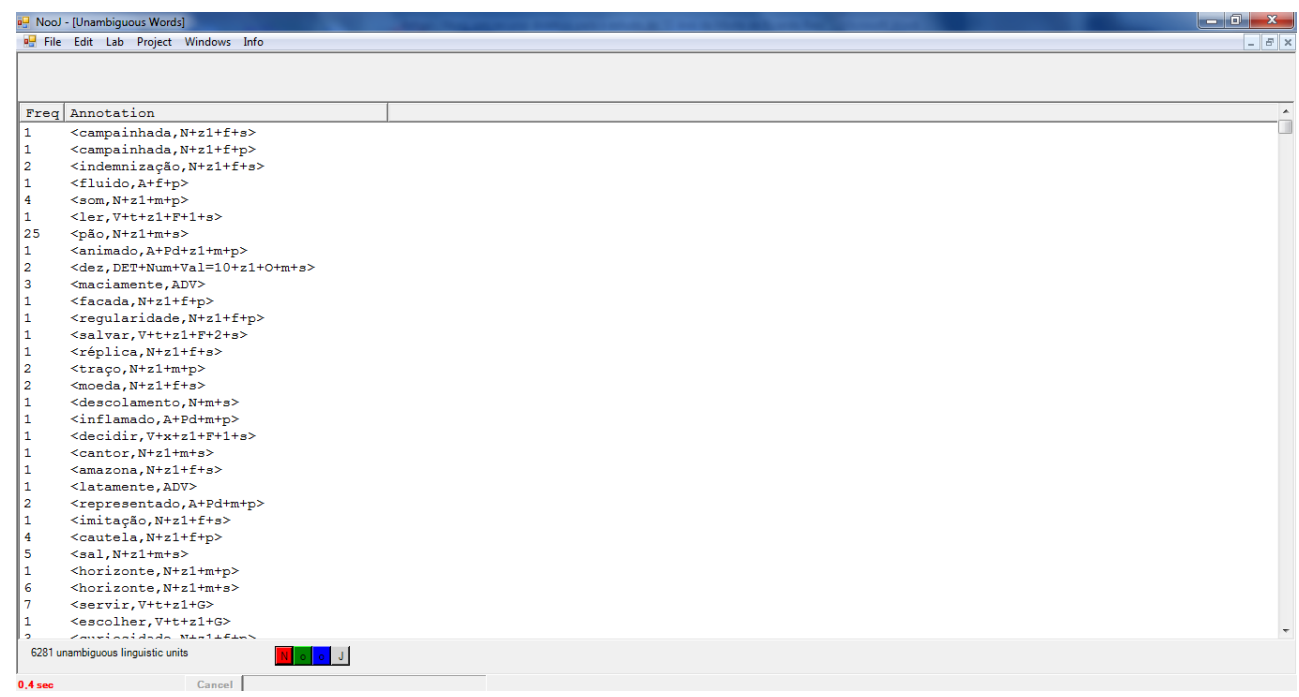


As anotações também podem ser visualizadas, frase a frase. Por exemplo, na figura 4, podemos verificar as anotações da primeira frase do romance "O Ano da morte de Ricardo Reis".

Fig. 4 Anotações da primeira frase do romance "O Ano da morte de Ricardo Reis"

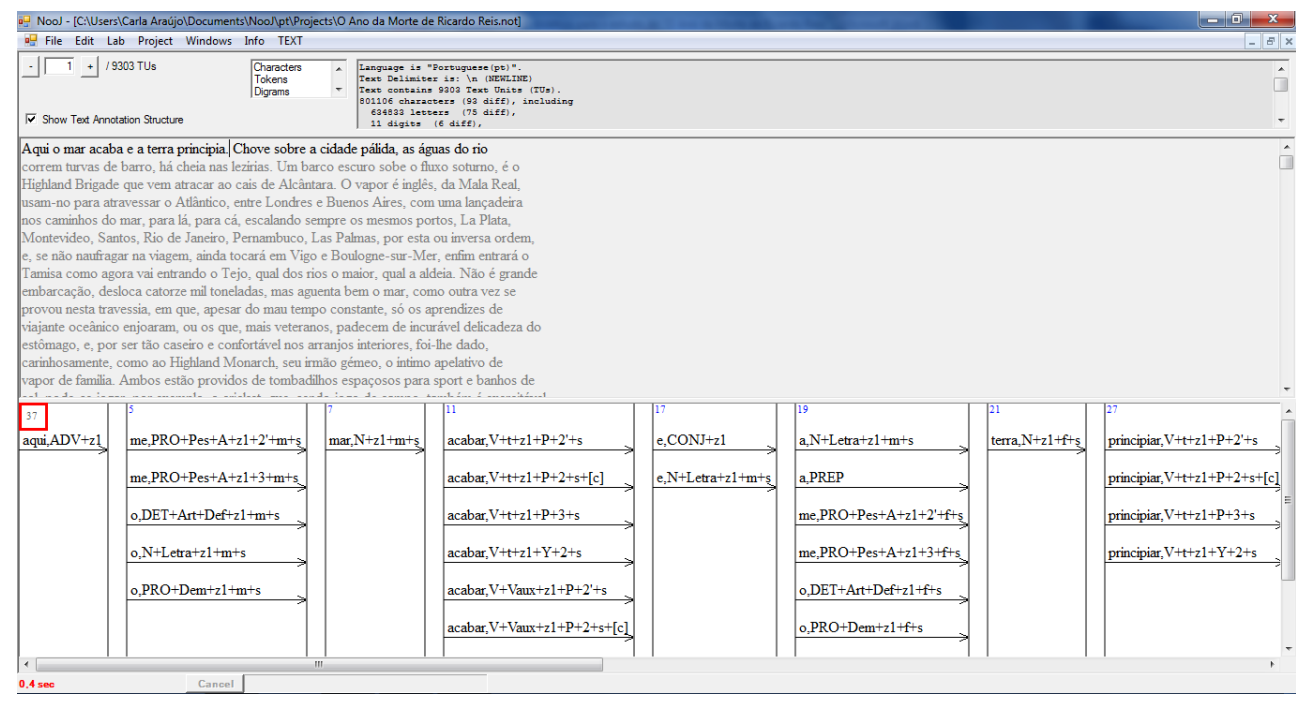

Tendo por base a referida metodologia, como podemos constatar na tabela 3, no romance "O Ano da morte de Ricardo Reis", foi possível delimitar doze campos temáticos de diferentes domínios: o campo temático do domínio de poder foi delimitado através das palavras-tema "há"/"Há", "tem"/"Tem", "pode"/"Pode", "grande"/"Grande", "tinha"/"Tinha", "quer"/"Quer"; o campo temático de contemplação foi delimitado através das palavras-tema "ver", "sabe"/"Sabe", "olhos", "saber"/"Saber", "verdade", "cabeça"; o campo temático do domínio de ação, a partir das palavras-tema "mão", "fazer", "faz"/"Faz", “dar", "mãos", "deu”; o campo temático de espaço, relacionado com as palavras-tema "casa"/“Casa", "hotel"/"Hotel”, "quarto", "lugar"; o campo temático do domínio de sociedade foi construído a partir das palavras-tema "homem"/“Homem", "homens"; "gente"; "mulher", "mulheres", "pessoas", "vida", "mundo"; o campo temático do domínio de estratificação social foi delimitado através das palavras-tema "doutor"/“Doutor", "senhor"/"Senhor"; o campo temático do domínio de período temporal foi delimitado através das palavras-tema "Tempo", "vez", "dia"/"Dia", “dias", "noite", "vezes", "caso", "anos", "horas"; o campo temático de família foi delimitado através da palavra-tema "pai"; o campo temático do domínio de deambulismo, a partir das palavrastema "vai"/"Vai", "vem", "vão", "ir", "veio", "porta", "lado"; o campo temático de religião, relacionado com a palavra-tema "deus"/”Deus"; o campo temático do domínio de 
diálogo foi construído a partir das palavras-tema "dizer"/“Dizer", “disse"/"Disse", "palavras", "diz", "nome”, "falar", "palavra", "coisa", "coisas"; o campo temático do domínio de destruição foi delimitado através da palavra-tema "morte"/"Morte".

Tabela 3. Campos temáticos de "O Ano da morte de Ricardo Reis"

\begin{tabular}{|c|c|}
\hline Palavras-tema & CAMPOS TEMÁticos \\
\hline $\begin{array}{l}\text { "há"/"Há"; } \quad \text { "tem"/"Tem"; "pode"/"Pode"; } \\
\text { "grande"/"Grande"; "tinha"/"Tinha"; "quer"/"Quer" }\end{array}$ & Campo Temático de Poder \\
\hline $\begin{array}{l}\text { "ver"; "sabe"/"Sabe"; "olhos"; "saber"/"Saber"; } \\
\text { "verdade"; "cabeça" }\end{array}$ & Campo Temático de Contemplação \\
\hline "mão"; “fazer”; “faz"/’Faz"; “dar”; “mãos”; “deu” & Campo Temático de Ação \\
\hline "casa"/“Casa”; "hotel”/”Hotel”; "quarto”; "lugar" & Campo Temático de Espaço \\
\hline $\begin{array}{l}\text { "homem"/"Homem"; "homens"; "gente"; "mulher"; } \\
\text { "mulheres"; "pessoas"; "vida"; "mundo" }\end{array}$ & Campo Temático de Sociedade \\
\hline "doutor"/“Doutor”; "senhor"/”Senhor" & Campo Temático de Estratificação Social \\
\hline $\begin{array}{l}\text { "Tempo"; "vez"; "dia"/’Dia"; "dias"; "noite"; "vezes"; } \\
\text { "caso"; "anos"; "horas" }\end{array}$ & Campo Temático de Período Temporal \\
\hline "pai” & Campo Temático de Família \\
\hline "vai"/”Vai"; "vem"; "vão"; “ir”; "veio"; "porta"; "lado" & Campo Temático de Deambulismo \\
\hline “deus"/”Deus" & Campo Temático de Religião \\
\hline $\begin{array}{l}\text { "dizer"/“Dizer"; "disse"/"Disse”; "palavras"; "diz"; } \\
\text { "nome"; "falar"; "palavra"; "coisa”; "coisas" }\end{array}$ & Campo Temático de Diálogo \\
\hline "morte"/"Morte" & Campo Temático de Destruição \\
\hline
\end{tabular}

\section{Nooj, um possível recurso didático para o estudo de "O Ano da Morte de Ricardo Reis", de José Saramago}

Quer no contexto nacional quer internacionalmente, os projetos, programas e atividades pedagógicas desenvolvidos nas últimas décadas enfatizam o valor das TIC no âmbito escolar, tendo em vista práticas pedagógicas inovadoras e atuais, promotoras, principalmente, da aprendizagem dos alunos (Conselho Nacional de Educação, 2017). O Programa de Português do Ensino Secundário (Buescu, 2014), para o 12. . ano, no domínio da Educação Literária, recomenda o estudo do romance "O Ano da Morte de Ricardo Reis", de José Saramago (Buescu, 2014, p. 27). No âmbito da abordagem pedagógico-didática do romance "O Ano da Morte de Ricardo Reis", entendemos que o estudo desta obra literária 
pode ser enriquecido com o auxílio da ferramenta tecnológica Nooj, que faculta o acesso sistematizado a todas as formas do corpus, ou seja, a todas as palavras usadas pelo autor na obra. Nesse sentido, a seguir, apresentamos exemplos de tarefas que poderão ser realizadas em contexto de aulas de estudo do romance "O Ano da Morte de Ricardo Reis".

A análise das palavras-tema do corpus em estudo, que integram a tabela 2, do ponto 2 deste trabalho, remete os alunos para fenómenos de ambiguidade lexical, por isso, o professor deve organizar atividades orientadoras da resolução desses problemas de ambiguidade, através dos quais os alunos identifiquem casos de homonímia e de polissemia (Chaves, 2013) e descubram o significado contextual das palavras do romance "O Ano da Morte de Ricardo Reis". Para tal, os estudantes poderão observar e analisar as concordâncias relativas às palavras-tema do romance "O Ano da Morte de Ricardo Reis", dadas automaticamente pelo Nooj, e consultar as definições patentes no dicionário ${ }^{3}$ relativas às mesmas. A realização desta tarefa, por um lado, permitirá aos estudantes conhecer os significados reais das palavras-tema do romance "O Ano da Morte de Ricardo Reis", por outro lado, orientá-los-á na delimitação de campos temáticos através do conhecimento do significado real de cada uma das palavras-tema do romance.

Assim, o professor poderá propor aos alunos a realização de tarefas como as que se apresentam na tabela 4, em que os alunos, a partir da análise das palavras-tema apresentadas na tabela 2 , do ponto 2 deste trabalho, poderão construir campos temáticos presentes no romance "O Ano da Morte de Ricardo Reis".

\footnotetext{
${ }^{3}$ Dicionário da Língua Portuguesa da Porto Editora ${ }^{\circledR}$ (versão on-line): http://www.infopedia.pt/.
} 
Tabela 4. Exemplo de atividade - Campos temáticos de “O Ano da morte de Ricardo Reis"

\begin{tabular}{|l|l|}
\hline PALAVRAS-TEMA & CAMPOS TEMÁTICOS \\
\hline $\begin{array}{l}\text { Exemplo: } \\
\text { "há"/"Há"; "tem"/"Tem"; "pode"/"Pode"; } \\
\text { "grande"/"Grande"; "tinha"/"Tinha"; "quer"/"Quer" }\end{array}$ & Campo Temático de Poder \\
\hline & 1. Campo Temático de \\
\hline & 2. Campo Temático de \\
\hline & 3. Campo Temático de \\
\hline & 4. Campo Temático de \\
\hline & 5. Campo Temático de \\
\hline & 6. Campo Temático de \\
\hline & 7. Campo Temático de \\
\hline & 8. Campo Temático de \\
\hline & 9. Campo Temático de \\
\hline & 10. Campo Temático de \\
\hline & 11. Campo Temático de \\
\hline
\end{tabular}

\section{Considerações finais}

A análise lexicométrica do romance "O Ano da morte de Ricardo Reis", de José Saramago, constitui uma possibilidade de operacionalização didática, que apresenta o programa computacional Nooj como um recurso didático possível, dado que faculta o conhecimento cabal da tessitura lexical da obra, permitindo aos alunos o desenvolvimento da sua competência lexical, através de práticas pedagógicas de análise textual que rentabilizam as potencialidades das novas tecnologias e convocam a participação ativa de alunos e professores, tendo em vista a aprendizagem efetiva e consolidada da língua portuguesa.

Nesse sentido, consideramos que a aula de Português que convoca o uso das tecnologias que o mundo atual nos proporciona poderá configurar um espaço sustentado de uma pedagogia e didática da Língua e Literatura renovadas, capazes de contribuir para o envolvimento dos alunos na aprendizagem e indo de encontro a modelos tradicionais de ensino, que giram em torno de alunos ouvintes, professores transmissores e de conteúdos. Por conseguinte, o grande desafio que se coloca a alunos e professores é rentabilizar recursos tecnológicos propiciadores de novas experiências pedagógicas, ancoradas no mundo de hoje e, simultaneamente, promotoras da autonomia, interesse e acesso ao conhecimento linguístico para todos os alunos de Português. 


\section{Referências}

Buescu, H., C. et al. (2014). Programa e Metas Curriculares de Português Ensino Secundário. Lisboa: Ministério da Educação e Ciência.

Chaves, R. P. (2013). "Organização do léxico". In: Raposo, E. (Org.) (2013). Gramática do português. Lisboa: Fundação Calouste Gulbenkian, pp. 190-196.

Conselho Nacional de Educação (2017). Aprendizagem, TIC e Redes Digitais. Disponível em http://www.cnedu.pt/content/edicoes/seminarios_e_coloquios/LIVRO_TIC_RedesDigitais.pdf

Dicionário da Língua Portuguesa da Porto Editora ${ }^{\circledR}$ (versão on-line): http://www.infopedia.pt/.

Galisson, R. \& Coste, D. (1983). Dicionário de Didáctica das Línguas. Coimbra: Livraria Almedina.

Genouvrier, E. \& Peytard, J. (1974). Linguística e Ensino do Português. Coimbra: Livraria Almedina, pp. 257-365.

Mendes, A. (2013). "Processos de gramaticalização". In Raposo, E. (Org. ) (2013). Gramática do português. Lisboa: Fundação Calouste Gulbenkian, pp. 249-292.

Mota, C., Carvalho, P. \& Barreiro, A. (2016). "Port4NooJ v3.0: Integrated Linguistic Resources for Portuguese NLP". In: Proceedings of the 10th edition of the Language Resources and Evaluation Conference (LREC 2016). Ed. by Nicoletta Calzolari et al. Portoro, Slovenia, pp. -.

Raposo, E. B. P. (2013). “Estrutura da frase”. In Raposo, E. (Org. ) (2013). Gramática do português. Lisboa: Fundação Calouste Gulbenkian, pp. 330-336.

Saramago, J. (1984). O Ano da Morte de Ricardo Reis. Lisboa: Editorial Caminho.

Silberztein, M. (2003). Nooj Manual. Internet. Disponível em http://www.nooj4nlp.net/NooJ\%20Manual.pdf 